ISSW:2597-8748 @

\title{
Isolation and Characterization of Microcrystalline Cellulose Derived from Plants as Excipient in Tablet: A Review
}

\author{
Nagina Belali ${ }^{1,2, *}$, Anis Y. Chaerunisaa ${ }^{2}$, Taofik Rusdiana ${ }^{2}$ \\ 1. Department of Pharmaceutics, Faculty of Pharmacy, Kabul University, Jamal Mena, 1006, Kabul, \\ Afghanistan \\ 2. Department of Pharmaceutics, Faculty of Pharmacy, Universitas Padjadjaran, Jl. Raya Jatinangor KM \\ 21.5 Bandung-Sumedang, 45363
}

Received: 9 May 2019/Revised: 15 May 2019/Accepted: 17 May 2019/ Published: 13 Jun 2019

\begin{abstract}
Microcrystalline cellulose (MCC) is a versatile and frequently used material in different industries such as pharmaceuticals production, medical, cosmetics, and food industry. Its qualities of being inert, economic, compatibility, compatibility, non-toxicity, biodegradability, good mechanical properties, high surface area, variety and availability of different grades and biocompatibility has made it very popular. Many research has been done on MCC to isolate it from different plant sources that are economical and eco-friendly. MCC is extracted from $\alpha$ cellulose that is abundant in nature as most of MCC is produced from wood. However, new eco-friendly sources with changes in methods of isolation have been applied for the production of MCC. In this review MCC isolated from different plant-based resources, extraction process parameters, the origin of raw material and its influence on critical material attributes of MCC has been outlined and discussed thoroughly. Since these critical material attributes have a significant effect on tablet making process parameters (compressibility, compatibility and etc) and its post-compression characters. Keywords: Microcrystalline cellulose, isolation, characterization, raw material, tabletability
\end{abstract}

\section{Introduction}

Microcrystalline cellulose (MCC) is a partially depolymerized purified derivative of $\alpha$-cellulose that has alpha bonds and cannot be digested and absorbed in the human body because humans do not have the enzyme to break those bonds. Microcrystalline cellulose is a white, crystalline powder that does not have any taste or odor. This makes it a good choice to be applied in different industries such as pharmaceutical, food, and cosmetics [1]. It has marked characteristics of good strength, fibrous nature, crystallinity, light in weight, biocompatibility, water insolubility, and biodegradability that makes it a choice excipient in today's era of renewables with diverse applications. In the modern era, environmental issues are of significance, and most materials are expected to be green that won't harm our environment and are degradable from natural sources, however, most of MCC is produced from wood pulp and purified cotton that is harmful to the ecosystem. Therefore, through last two decade efforts has been done to isolate MCC from natural sources and wastes of plants that are either eco-friendly and economical, as it can be isolated from any material that has high cellulose concentration [2]. Many studies have reported different cheap sources that would be discussed and their properties in sense of how good they are along with results of their characterization would be presented.

MCC was first discovered by Battista and Smith in 1955 and was commercialized by the name of Avicel. In 1964 it was introduced as a direct compression tableting excipient under name of Avicel PH that was later registered in the National formulary, in 1966 until now it is produced by more than 10 suppliers around the world [3]. MCC is of significance in regards to its unique characteristics that make it an optimum excipient such as selfdisintegrating properties, water retaining properties, good binding agent, compactibility at 
low pressures, compatible to most of APIs and even has suspension stabilizing effects [4] [5]. MCC is generally used as a filler due to its binding properties and is preferred as one of the best filler and binder for direct compression, because of its good compactibility and compressibility properties [6][7]. Its properties have been further enhanced by combining it with other excipients or co-processing it with other excipients to increase the functionality of MCC. A study done by Nagin K. Patel in 1992 reveals that a combination of lactose with $50 \%$ of microcrystalline cellulose give very good compressible properties to tablets [8].

Rowe et al. reported that the compactability index among five different brands of MCC was different, also most important is crystallinity of MCC that can significantly affect the dissolution of API [9]. Another study by Suzuki et al reported the effects of crystallinity on the dissolution of tablets, where tablets of acetaminophen were produced with MCC that was pulverized to decrease its crystallinity. Tablets of acetaminophen with MCC having crystallinity between $25-12 \%$ showed a significant increase in dissolution of the drug [3]. Kimie et al also reported how the presence of MCC even in small amounts can affect the stability of acetylsalicylic acid by hydrolysis since MCC is very hygroscopic. Also, the decrease in crystallinity of MCC was depicted intentionally to see its effects on the hydrolysis of API, as it tends to absorb more moisture and water when crystallinity is decreased [10].

As mentioned above a variety of sources have been employed for isolation of MCC that have different compactability and different attributes as their raw materials and manufacturing conditions are different. Significant differences in lignin content, hemicellulose sugars, and composition, particle size, and flow properties were analyzed among four brands of MCC from Finland, India, Ireland, and Japan by M. Landin et al, that correlated with water-cellulose interaction and particle size with flow properties [11]. A different source of woods and fibers have variability of chemical composition in terms of hemicelluloses, lignin, and proportions of cellulose, and structural organizations [12] that's why MCC isolated from the different source even on the basis of region, would have different characteristics that we aim to study and explain well in the present study.

\section{Discussion}

Microcrystalline Cellulose (MCC) isolation has been done by a variety of techniques the general process has been presented in figure I. Foremost the number of lignocellulose compounds should be evaluated in plant as it is made of cellulose, hemicellulose, and lignin, lignin is the most difficult to be separated from cellulose and is done by physical, biological, chemical and combined processes. After delignification and bleaching, MCC is usually produced by acid hydrolysis with a mineral acid that cleaves the paracrystalline or amorphous regions while crystal domains having high resistance would be maintained, and slurry obtained is spray dried, type of acid used, time of

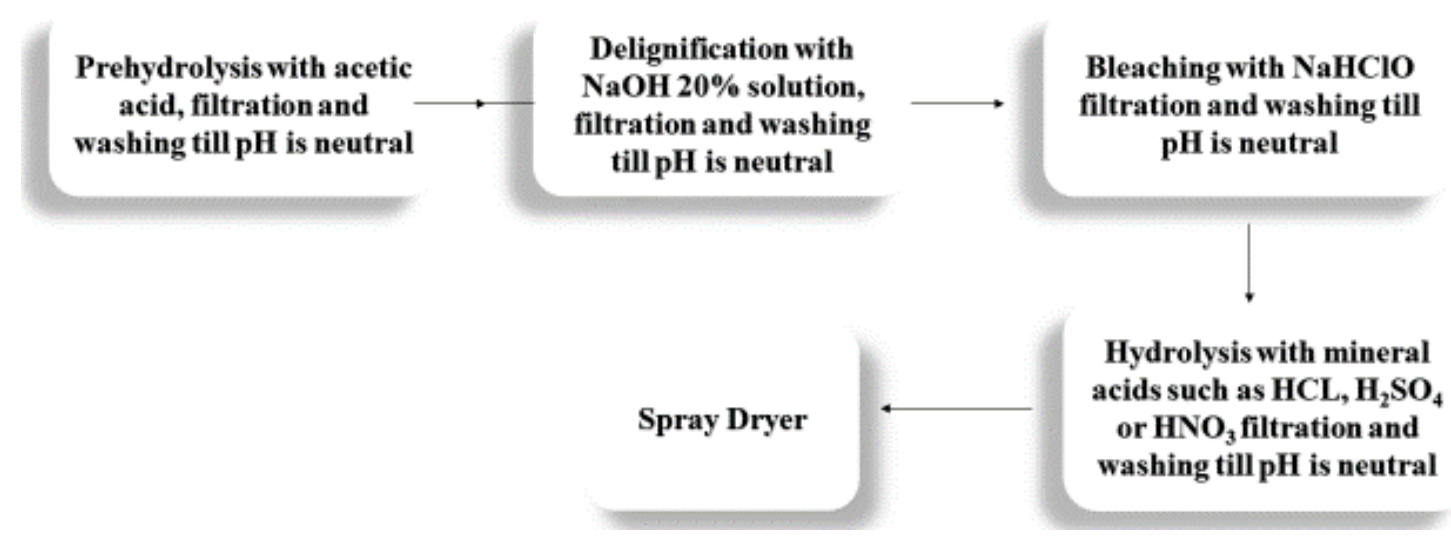

Figure 1. MCC manufacturing steps 
application and temperature play an important role in particle size, crystallinity, and morphology of MCC. Drying step is a critical step that will affect the particle size distribution and moisture content of MCC that are critical attributes for excipients, MCC can be dried by Fluidized bed dryer, freeze drying, microwaves and static oven after which MCC is grinded to desired particle size [13].

On industrial scale cellulose is produced mostly from cotton, wood pulp and lignocellulosic that requires steps of delignification and bleaching but Olevira et al prepared MCC from Bacterial cellulose, Acetobacter xylinus (is the only known species capable of producing cellulose on commercial level) where these steps are not needed, and thus have different properties such as lower thermal stability [14]. MCC isolated from Jute by Jahan et al concluded that high acid concentration method produced MCC with better properties than low acid concentration, as their MCC had good thermal stability and crystallinity of $74 \%$, which in our point of view is because of using organic acid as they had applied formic acid but in high concentration [15]. MCC produced by different methods of acid hydrolysis from different raw material with resulting crystallinities has been presented in table 1.

Lower crystallinity index shows that the amorphous regions were removed with hydrothermal treatment [13]. The total amount of

Table 1. Processing conditions and raw materials of MCC

\begin{tabular}{|c|c|c|c|}
\hline Raw material & Acid Hydrolysis & Crystallinity & Reference \\
\hline Wood pulp cellulose & Sulphuric acid & $\begin{array}{l}\text { Not } \\
\text { mentioned }\end{array}$ & {$[16]$} \\
\hline Esparto grass fibers & Hydrochloric acid & $\begin{array}{l}\text { Not } \\
\text { mentioned }\end{array}$ & {$[17]$} \\
\hline Oil palm empty fruit bunch & Sulphuric Acid & $87 \%$ & {$[18]$} \\
\hline $\begin{array}{l}\text { Cellulose produced in the culture medium of } \\
\text { static Acetobacter xylinum }\end{array}$ & Sulphuric Acid & $69 \%$ & [14] \\
\hline Rice straw and Banana plant waste & $\begin{array}{l}\text { Alkaline acid pulping }(10 \% \mathrm{NaOH} \text {, } \\
\left.\mathrm{H}_{2} \mathrm{SO}_{4}\right) \text {, acid-alkaline }\left(5 \% \mathrm{H}_{2} \mathrm{SO}_{4}, 10 \%\right. \\
\mathrm{NaOH})\end{array}$ & $65 \%$ & [19] \\
\hline Cotton fabrics waste & Hydrochloric acid at $110-170^{\circ} \mathrm{C}$ & $58.4 \%$ & {$[20]$} \\
\hline Jute fiber & Formic acid $90 \%$ & $74 \%$ & {$[15]$} \\
\hline Cotton silver & Sulphuric acid 55\% & $57.18 \%$ & {$[21]$} \\
\hline Roselle fibers & Hydrochloric acid & $78 \%$ & {$[22]$} \\
\hline Pomelo Peel & Hydrochloric acid & $40.3 \%$ & {$[23]$} \\
\hline Olong Tea waste & Hydrochloric acid & $81 \%$ & {$[24]$} \\
\hline
\end{tabular}


water sorbed by MCC is proportional to its amorphous material, thus MCC that has lower crystallinity would have more sorbed water compared to those with high crystallinity, that can have a significant impact on the stability of water sensitive APIs and would degrade [7]. However, dissolution rates of acetaminophen tablets reduced with decrease in crystallinity to about $37 \%$, because water penetration into tablets is increased Another study done by Awa et al, effect of MCC crystallinity on Acetylsalicylic acid tablets showed that MCC with low crystallinity can hydrolyze ASA to salicylic acid, that affects stability of dosage form that is a much more important aspect, that reveals the importance of MCC crystallinity on pharmaceutical properties of tablets [10].

Moisture content is also critical property as it has been seen that it can influence compaction properties, tensile strength, and viscoelastic properties of MCC in tablets. When the moisture level is lower than 3\% it won't affect compaction properties of MCC, however, increase in moisture content to an optimum level will eventually increase the strength of the tablet, that might be because of decrease in interparticular distance and increase in intermolecular attraction forces [25]. More than $3 \%$ of water content in microcrystalline cellulose would disrupt hydrogen bonds that crosslink hydroxyl groups on the cellulose chain, resulting in a strength decrease [5].

Moisture content, particle size, tapped density, conductivity, and $\mathrm{pH}$ have a significant effect on tabletability of MCC, although conductivity and $\mathrm{pH}$ have not been incorporated in Critical Material Attributes (CMA) of MCC. Thoorens et al reported that tapped density might be critical to tabletability in addition to particle size and moisture content of MCC, thus concluded that formulators should identify CMAs to improve quality of the product [26]. Particle size has minimum effects on tabletability, however, variability in particle size can impact on flowability which will, in turn, affect tablet hardness, weight uniformity, content uniformity. Using fine MCC would promote tablet strength however it would affect flowability because it increases cohesiveness [27]. A technical note by Gamble et al on particle size distribution and its effects on flow properties on conventional MCC was elucidated that the proportion of agglomerates of MCC particles in MCC especially in avicel PH200 can improve its flowability, because of increase in particle size but it can promote segregation of particles on basis of their size that would eventually affect the content uniformity [28].

Another property that was reported to have a significant impact on tabletability is particle morphology, that is explained in terms of particles length and diameter, as particles with higher L/D ratio had better tablet strengths and another study reported MCC morphology can influence the dissolution of the drug [29]. Hydrolysis treatment affects the size and surface morphology of MCC and level of smoothness of particles, fewer researches had used TEM to examine the surface morphology of MCC but results of SEM presented in most of the researches presented morphology of MCC particles and no significant difference was seen in their morphology presented in the table. Trache et al and Adel et al reported that the diameter of MCC from the market had large diameter than MCC isolated from lignocellulosic raw materials [17][30].

MCC is usually spray-dried that promotes porous structure and gives it a low bulk density that would facilitate compressibility that is one of the attributes that makes MCC so popular, thus this result can be drawn that low bulk density can improve tabletability, although it would negatively affect flowability [8]. This finding is inconsistence with study by Dolker in 1993, that mentioned MCC has high intraparticle porosity of $90-95 \%$ of the surface area being internal, this high porosity promotes swelling and disintegration of MCC tablets, that is related to water penetration in the hydrophilic matrix of tablet by disruption in hydrogen bonds, at the same time if compaction force is increased it would decrease water penetration into the tablet and hence increasing disintegration time [8] [26].

Nowadays, MCC is a commercial excipient that is available since last 60 years with a price of almost 4 dollars per kilogram, which is comparable to or less than some other engineering fillers. It is 
produced worldwide by more than 10 companies, several methods have been used for isolation of pure MCC, physicochemical properties and mechanical characteristics of MCC is variable on the basis of the origin of raw materials and the extraction process that has been discussed in detail here and also presented by Thoorens et al.

\section{Conclusion}

Microcrystalline Cellulose is a diverse excipient with widespread application that is considered one of the best diluent. MCC is a cellulose derivative that is abundant in nature thus can be isolated from a number of raw materials, and a number of ecofriendly, cheap, waste managing methods have been applied for production of MCC. MCC has widespread application in different industries and as seen above it has been produced from different raw materials with variability in parameters of manufacturing process that has an impact on Critical Material Attributes, and because of this variability use of MCC from different suppliers with different sources and different methods of isolation should be validated, when used on industrial scale. CMAs of MCC such as particle size, moisture content, surface area, surface morphology do impact the tabletability of MCC as they influence flow properties of MCC. Since such critical attributes are confirmed when applied in specific formulations thus its control in different batches, by different suppliers and the different raw material is a difficult task. Thus policymakers, drug manufacturers and suppliers of excipients should synchronize their work so excipients processes and functionality can be understood well.

\section{References}

[1] Dutta R, Nath Y, Ochubiojo ME, Kumar A. Colloids and Surfaces B: Biointerfaces Extraction and characterization of microcrystalline cellulose from fodder grass ; Setaria glauca ( L ) P . Beauv, and its potential as a drug delivery vehicle for isoniazid, a first line antituberculosis drug. Colloids Surfaces B Biointerfaces [Internet]. Elsevier B.V.; 2013;108:85-9. Available from:

http://dx.doi.org/10.1016/j.colsurfb.2013.02. 016
[2] Oyeniyi Y.J, Itiola O.A. The Physicochemical characteristic of microcrystalline cellulose, derived from sawdust, Agricultural waste products. Int J Pharm Pharm Sci. 2012;4(2):3-6.

[3] Suzuki T, Nakagami H. Effect of crystallinity of microcrystalline cellulose on the compactability and dissolution of tablets. 1999;47:225-30.

[4] Abdul Khalil H. P. S.1 *, Tze Kiat Lai1, Ying Ying Tye1 , M. T. Paridah2, M. R. Nurul Fazita1, A. A. Azniwati1, Rudi Dungani3 and SR. preparation and Characterization of Microcrystalline Cellulose from Sacred Bali Bamboo as Reinforcing Filler in Seaweedbased Composite Film. fibers Polym. 2018;19(2):423-34.

[5] Doelker E, D. M, H. I, P. H-D. COMPARATIVE TABLETING PROPERTIES OF SIXTEEN. 1987;13:1847-75.

[6] Shlieout G, Arnold K. Powder and Mechanical Properties of Microcrystalline Cellulose With Different Degrees of Polymerization. 2002;3(2):1-10.

[7] Bolhuis GK, Armstrong NA. Excipients for direct compaction - an update. Int $J$ pharmaceutical Dev Technol [Internet]. 2006;11(1):111-24. Available from: https://doi.org/10.1080/10837450500464255

[8] Pate NK, Upadhyay AH, Bergum JS, Reier E. An evaluation of microcrystalline cellulose and lactose excipients using an instrumented single station tablet press. 1994;5173(94).

[9] Rowe R, McKillop A, Bray D. The effect of batch and source variation on the crystallinity of microcrystalline cellulose. Indian J Pharm Sci [Internet]. 1994;101(1-2):169-72. Available from: https://doi.org/10.1016/03785173(94)90087-6

[10] Awa K, Shinzawa H, Ozaki Y. The Effect of Microcrystalline Cellulose Crystallinity on the Hydrophilic Property of Tablets and the Hydrolysis of Acetylsalicylic Acid as Active Pharmaceutical Ingredient Inside Tablets. 2015;16(4):865-70. 
[11] Landína M, R.Martínez PL, Gómez A, Soutoa C, Concheiroa A, Rowe RC. Effect of country of origin on the properties of microcrystalline cellulose. Int $\mathrm{J}$ Pharm [Internet]. 1993;91(2-3):123-31. Available from: $\quad$ https://doi.org/10.1016/03785173(93)90331

[12] Thoorens G, Krier F, Leclercq B, Carlin B, Evrard B. Microcrystalline cellulose, a direct compression binder in a quality by design environment - A review. Elsevier BV [Internet]. Elsevier B.V.; 2014; Available from:

http://dx.doi.org/10.1016/j.ijpharm.2014.06. 055

[13] Trache D, Hussin MH, Tan C, Chuin H, Sabar S, Fazita MRN, et al. International Journal of Biological Macromolecules Microcrystalline cellulose: Isolation, characterization and bio-composites application - A review. Int J Biol Macromol [Internet]. Elsevier B.V.; 2016;93:789-804. Available from: http://dx.doi.org/10.1016/j.ijbiomac.2016.09 .056

[14] Oliveira RL De, Assunc RMN De, Carvalho GO, Filho GR, Messaddeq Y, Jose S. Synthesis and characterization of microcrystalline cellulose produced from bacterial cellulose. 2011;703-9.

[15] Jahan MS, Saeed A, He Z. Jute as raw material for the preparation of microcrystalline cellulose. 2011;451-9.

[16] Sun CC. Mechanism of moisture induced variations in true density and compaction properties of microcrystalline cellulose. Indian J Pharm Sci. 2008;346:93-101.

[17] Battista OA, Smith PA, Hook M. Microcrystalline cellulose the oldest polymer finds new industrial uses. Ind Eng Chem. 1962;

[18] Trache D, Donnot A, Khimeche K, Benelmir R, Brosse N. Physico-chemical properties and thermal stability of microcrystalline cellulose isolated from Alfa fibres. Carbohydr Polym [Internet]. Elsevier Ltd.; 2014;104:223-30. Available from: http://dx.doi.org/10.1016/j.carbpol.2014.01. 058

[19] Haafiz MKM, Hassan A, Zakaria Z, Inuwa IM. Isolation and characterization of cellulose nanowhiskers from oil palm biomass microcrystalline cellulose. Carbohydr Polym [Internet]. Elsevier Ltd.; 2014;103:119-25. Available from: http://dx.doi.org/10.1016/j.carbpol.2013.11. 055

[20] El-zawawy MMIWK, Ju Y, Heinze T. Cellulose and microcrystalline cellulose from rice straw and banana plant waste: preparation and characterization. 2013;240316.

[21] Sheng S, Meiling Z, Chen L, Wensheng H, Zhifeng Y. Extraction and characterization of microcrystalline cellulose from waste cotton fabrics via hydrothermal method. Waste Manag [Internet]. Elsevier Ltd; 2018;82:139-46. Available from: https://doi.org/10.1016/j.wasman.2018.10.02 3

[22] Kale RD, Shobha P, Vikrant B. Extraction of Microcrystalline Cellulose from Cotton Sliver and Its Comparison with Commercial Microcrystalline Cellulose. J Polym Environ. Springer US; 2017;0(0):0.

[23] Kia L, Jawaid M, Ariffin H, Alothman OY. International Journal of Biological Macromolecules Isolation and characterization of microcrystalline cellulose from roselle fibers. Int J Biol Macromol [Internet]. Elsevier B.V.; 2017;103:931-40. Available from: http://dx.doi.org/10.1016/j.ijbiomac.2017.05 .135

[24] Liu Y, Liu A, Ibrahim SA, Yang H, Huang W. International Journal of Biological Macromolecules Isolation and characterization of microcrystalline cellulose from pomelo peel. Int J Biol Macromol [Internet]. Elsevier B.V.; 2018;111:717-21. Available

from: https://doi.org/10.1016/j.ijbiomac.2018.01.0 98

[25] Zhao T, Chen Z, Lin X, Ren Z, Li B, Zhang $Y$. Preparation and characterization of 
microcrystalline cellulose ( MCC ) from tea waste. Carbohydr Polym [Internet]. Elsevier; 2018;184(September 2017):164-70. Available from: https://doi.org/10.1016/j.carbpol.2017.12.02 4

[26] Thoorens G, Krier F, Rozet E, Carlin B, Evrard B. Understanding the impact of microcrystalline cellulose physicochemical properties on tabletability. Int $\mathrm{J}$ Pharm [Internet]. Elsevier B.V.; 2015;490(1-2):4754. Available from: http://dx.doi.org/10.1016/j.ijpharm.2015.05. 026

[27] Joseph Kushner I, Langdon BA, Hiller JONI, Carlson GT. Examining the Impact of Excipient Material Property Variation on Drug Product Quality Attributes : A QualityBy-Design Study for a Roller Compacted,
Immediate Release Tablet. 2011;100(6):113.

[28] Gamble JF, Chiu W, Tobyn M. Investigation into the impact of sub-populations of agglomerates on the particle size distribution and flow properties of conventional microcrystalline cellulose grades. 2011;16(May 2010):542-8.

[29] Friedman R. Pharmaceutical quality systems: US perspective. Pharmaceutical. In: Quality System (ICH Q10) Conference. 2011.

[30] Adel AM, El-wahab ZHA, Ibrahim AA, Alshemy MT. Characterization of microcrystalline cellulose prepared from lignocellulosic materials. Part II : Physicochemical properties. Carbohydr Polym [Internet]. Elsevier Ltd.; 2011;83(2):676-87. Available from: http://dx.doi.org/10.1016/j.carbpol.2010.08. 039 